\title{
CHARACTERIZATION OF A YEAST D-AMINO ACID OXIDASE MICROBIOSENSOR FOR D-SERINE DETECTION IN THE CENTRAL NERVOUS SYSTEM
}

\author{
Pierre PERNOT ${ }^{1}$, Jean-Pierre MOTHET ${ }^{2}$, Oleg SCHUVAILO ${ }^{3,4}$, Alexey SOLDATKIN ${ }^{4}$, \\ Loredano POLLEGIONI ${ }^{5}$, Mirella PILONE ${ }^{5}$, Marie-Thérèse ADELINE ${ }^{6}$, Raymond \\ CESPUGLIO ${ }^{3}$ and Stéphane MARINESCO $O^{1,7, *}$
}

${ }^{1}$ CNRS, Institut de Neurobiologie Alfred Fessard - FRC2118, Laboratoire de Neurobiologie Cellulaire et Moléculaire - UPR9040, 91198 Gif sur Yvette, FRANCE.

${ }^{2}$ INSERM U862, Université Bordeaux 2, Institut Magendie, 146 rue Léo Saignat, 33077 Bordeaux, FRANCE.

${ }^{3}$ EA4170, Université Claude Bernard Lyon I, 8 avenue Rockefeller, 69373 Lyon, FRANCE.

${ }^{4}$ Institute of Molecular Biology and Genetics, National Academy of Science of Ukraine, 150 zabolotny Str, $03143 \mathrm{Kiev}$, UKRAINE.

${ }^{5}$ Dept Biotechnology and Molecular Sciences, University of Insubria, Varese, ITALY.

${ }^{6}$ CNRS, Institut de Chimie des Substances Naturelles, 91198 Gif sur Yvette, FRANCE.

${ }^{7}$ INSERM U628, Université Claude-Bernard-Lyon I, 69373 Lyon Cedex 08, France.

* corresponding author: Stéphane Marinesco, Institut National de la Santé et de la Recherche Médicale U628, Université Claude-Bernard-Lyon I, 8 avenue Rockefeller, 69373 Lyon Cedex 08, France.

Tel : +33 (0)4 78777041, Fax : +33 (0)4 78777150, Email : stephane.marinesco@univ-lyon1.fr

Word count: abstract 218, text + references + figure captions 6654 . 


\begin{abstract}
$\mathrm{D}$-serine is an endogenous ligand for $N$-methyl D-aspartate (NMDA) receptors and alterations in its concentration have been related to several brain disorders, especially schizophrenia. It is therefore an important target neuromodulator for the pharmaceutical industry. To monitor Dserine levels in vivo, we have developed a microbiosensor based on cylindrical platinum microelectrodes, covered with a membrane of poly-phenylenediamine (PPD), and a layer of immobilized D-amino acid oxidase from the yeast Rhodotorula gracilis (RgDAAO). By detecting the hydrogen peroxide produced by enzymatic degradation of $\mathrm{D}$-serine, this microbiosensor shows a detection limit of $16 \mathrm{nM}$ and a mean response time of $2 \mathrm{~s}$. Interferences by ascorbic acid, uric acid, L-cysteine and by biogenic amines and their metabolites are rejected at more than $97 \%$ by the PPD layer. Although several D-amino acids are potential substrates for RgDAAO, Dserine was the only endogenous substrate present in sufficient concentration to be detected by our microbiosensor in the central nervous system. When implanted in the cortex of anesthetized rats, this microbiosensor detected the increase in concentration of D-serine resulting from its diffusion across the blood brain barrier after an intraperitoneal injection. This new device will make it possible to investigate in vivo the variations in $\mathrm{D}$-serine concentrations occurring under normal and pathological conditions, and to assess the pharmacological potency of new drugs designed to impact D-serine metabolism.
\end{abstract}


Alterations in brain concentrations of D-serine, the predominant D-amino acid in the mammalian central nervous system ${ }^{1}$, have been recently related to several neurological and psychiatric diseases ${ }^{2}$. D-serine is synthesized in glial cells ${ }^{3}$ and neurons ${ }^{4,5}$, through the racemization of $\mathrm{L}$-serine by serine racemase ${ }^{3}$. It is released by astrocytes in response to chemical stimulation by glutamate, or glutamate receptor agonists such as $\alpha$-amino-3-hydroxy-5methylisoxazole-4-propionate (AMPA), kainic acid, or (1S,3R)-1-aminocyclopentane-1,3dicarboxylic acid (t-ACPD) $)^{6,7}$. D-serine is an endogenous agonist of the glycine site of the Nmethyl-D-aspartate (NMDA) receptors ${ }^{8}$, and plays important roles in synaptic plasticity ${ }^{9,10}$ and in several neurological and psychiatric disorders, such as schizophrenia $^{11,}{ }^{12}$, ischemia ${ }^{13}$, Alzheimer's disease ${ }^{14}$ and amyotrophic lateral sclerosis ${ }^{15}$. In particular, D-serine concentration is decreased in the cerebrospinal fluid of schizophrenic patients ${ }^{16,17}$, and its administration enhances the therapeutic effects of known antipsychotic drugs ${ }^{18}, 19$. Notwithstanding the physiological importance of D-serine in these diseases, the variations in D-serine levels in the central nervous system (CNS) during behavior or pathological states remain largely unexplored. Also, the biochemical and cellular mechanisms controlling D-serine extracellular brain concentration are still elusive. To elucidate these important questions, the development of rapid and selective methods for monitoring $\mathrm{D}$-serine dynamics in the brain is of paramount importance.

Detection of free D-serine in the CNS has been reported using microdialysis ${ }^{20-23}$. Despite its impressive analytical power, microdialysis is limited by the large size of the probes used to collect brain samples and by the slow diffusion of molecules through the dialysis membrane. In particular, implantation of microdialysis probes into the CNS often causes lesions that impair the 
physiological processes taking place around the probe ${ }^{24-26}$. Moreover, microdialysis probes are too large to be inserted into brain slices or small structures of the rat or mouse CNS.

To overcome these technical limitations, we developed an enzymatic microbiosensor capable of detecting D-serine in vivo. Enzymatic biosensors have been used for monitoring extracellular levels of neurotransmitters like glutamate $^{27-31}$, adenosine $e^{32}$, adenosine triphosphate $^{33}$, choline ${ }^{34,35}$, acetylcholine ${ }^{36-38}$, as well as metabolic molecules like glucose ${ }^{39}$ or lactate $^{40}$. Moreover, D-amino acids (including D-serine) can be detected in food or beverages as markers of bacterial proliferation, using biosensors coated with the enzyme D-amino acid oxidase $(\mathrm{DAAO})^{41-44}$. However, these biosensors are too large to be inserted into the CNS of laboratory animals, and do not reach a sufficient detection limit to monitor physiological D-serine concentrations in the low micromolar range $\mathrm{e}^{21}$. In this study, we sought to optimize this principle to achieve successful electrochemical D-serine detection in the brain.

Our microbiosensor is based on a platinum microelectrode $(25 \times 150 \mu \mathrm{m})$ covered with a membrane of poly-m-phenylenediamine (PPD) for selectivity, and with a layer of D-amino acid oxidase purified from the yeast Rhodotorula gracilis (RgDAAO). This microbiosensor detects Dserine with an in vitro detection limit of $16 \mathrm{nM}$ and a mean response time of $2.3 \mathrm{~s}$. When used in the brain or in brain extracts, it is selective for D-serine over other endogenous amino acids or oxidizable molecules. Moreover, this microbiosensor can detect the basal D-serine extracellular concentration in the rat frontal cortex $(3.1 \mu \mathrm{M})$ and $\mathrm{D}$-serine diffusion through the blood brain barrier following an intraperitoneal injection. Parts of this study have been published in abstract form $^{45}$. 


\section{EXPERIMENTAL SECTION}

\section{Preparation of the enzyme}

Recombinant $R$. gracilis D-amino acid oxidase (RgDAAO, EC 1.4.3.3) was overexpressed in E. coli and purified as reported by Molla et al. ${ }^{46}$. The final enzyme preparation had a specific activity of $55 \mathrm{U} / \mathrm{mg}$ protein on D-serine, and was concentrated up to $58 \mathrm{mg} / \mathrm{ml}$ of RgDAAO in a solution containing $25 \mathrm{mg} / \mathrm{ml}$ bovine serum albumin (BSA, Sigma, St-Quentin Fallavier, France) and glycerol (1\%) in phosphate buffer $(0.02 \mathrm{M}, \mathrm{pH} 8.5)$. Pig kidney DAAO was purchased from Sigma and prepared following the same protocol as RgDAAO.

\section{Microbiosensor Preparation}

Biosensors were constituted of a $25 \mu \mathrm{m}$ diameter 90\% Pt / 10\% Ir wire (Goodfellow, Huntington, UK) glued to a $0.3 \mathrm{~mm}$ copper wire using electroconductive silver paint (Radiospares, Beauvais, France). It was then inserted into a pulled glass capillary (Harvard Apparatus, Edenbridge, UK) and the tip of the pipette was cut to let $150 \mu \mathrm{m}$ of the platinum wire protrude out of the glass. The junction between the platinum wire and the glass micropipette was sealed with epoxy resin (Araldite ${ }^{\circledR}$, Bostik, Paris, France). The electrodes were then washed for $30 \mathrm{~min}$ in $\mathrm{KOH} 0.5 \mathrm{M}$ and $20 \mathrm{~min}$ in ethanol. A PPD layer was electrodeposited by dipping the electrodes 20 minutes in a solution containing $100 \mathrm{mM}$ m-phenylenediamine in PBS $0.01 \mathrm{M}$ at $\mathrm{pH} 7.4$ under a constant potential of $+700 \mathrm{mV} v$ s. an $\mathrm{Ag} / \mathrm{AgCl}$ reference electrode. The enzyme layer was deposited by dipping the Pt tip of the electrodes in the DAAO solution (see above). Control microbiosensors (i.e. without DAAO) were produced by dipping the electrode in a 
solution of BSA (400 mg/ml) in phosphate buffered saline (PBS) $0.01 \mathrm{M}, \mathrm{pH} 7.4$ and 1\% glycerol. The enzyme was immobilized under saturated glutaraldehyde vapors for 120-135 s by placing the electrodes into a small chamber containing a few milliliters of a $50 \%$ glutaraldehyde solution (under a fume hood because of the toxicity of glutaraldehyde vapors). Electrodes were then kept at $-20^{\circ} \mathrm{C}$ in dry atmosphere for long-term storage.

All microbiosensors were tested for the detection of serotonin (5-HT, $20 \mu \mathrm{M}$ in PBS), Dserine ( $1 \mu \mathrm{M}$ in PBS) and $\mathrm{H}_{2} \mathrm{O}_{2}(1 \mu \mathrm{M}$ in PBS) before use. Only the electrodes showing more than $7 \mathrm{pA} / \mu \mathrm{M}$ D-serine and less than $4 \mathrm{pA} / 20 \mu \mathrm{M} 5$-HT were included in this study. To determine this threshold, we tested a total of 30 electrodes: D-serine sensitivity was $9.2 \pm 3.4$ $\mathrm{pA} / \mu \mathrm{M}$ and $16.7 \%$ were excluded using these criteria.

Microbiosensors used for in vivo experiments were covered with an additional Nafion membrane, to protect the enzyme layer during penetration into the brain. The tip of the electrode was dipped 5 times in Nafion 1\% (5\% commercial solution from Aldrich, Saint Quentin Fallavier, France, diluted in isopropanol) and allowed to dry for at least 10 minutes at room temperature ${ }^{31,34}$. This additional membrane did not change the sensitivity or the response time of the electrodes.

\section{Recordings}

All recordings were made either with a patch-clamp amplifier Geneclamp GC500 (Molecular Devices, Sunnyvale, CA) or with an electrochemistry amplifier VA-10 (NPI Electronics, Tamm, Germany) used with a 2 electrode potentiostat. Data acquisition was performed with an ITC-18 acquisition board (Instrutech, Port Washington, NY) driven with a homemade software based on Igor Pro 5.0 procedures (Wavemetrics, Eugene, OR). The 
oxidation current was sampled at $1 \mathrm{kHz}$ and averaged over 1000 data points, yielding a final sampling frequency of $1 \mathrm{~Hz}$.

In vitro calibrations were performed in standard solutions prepared with phosphate buffered saline (0.01 M, pH 7.4). The reference electrode was a chlorided silver wire placed directly into the recording chamber. Recordings were made in constant potential amperometry at $500 \mathrm{mV}$ vs. the $\mathrm{Ag} / \mathrm{AgCl}$ reference electrode. Calibration of the biosensors before and after in vivo experiments was performed in an artificial extracellular medium containing (in $\mathrm{mM}$ ): $\mathrm{NaCl}$ 126, $\mathrm{KCl} 1.5, \mathrm{KH}_{2} \mathrm{PO}_{4} 1.25, \mathrm{MgSO}_{4} 1.5, \mathrm{CaCl}_{2} 2$ and HEPES 10 (pH 7.4). All chemicals were purchased from Sigma-Aldrich (Saint-Quentin Fallavier, France).

\section{Preparation of brain samples}

Male Wistar rats (300-400 g) were decapitated under isofurane anesthesia, and the forebrain was removed and homogenized in $5 \mathrm{ml}$ of $5 \%$ trichloroacetic acid (TCA) to precipitate macromolecules. The homogenate was then centrifuged at $20000 \mathrm{~g}$ for $10 \mathrm{~min}$. TCA was extracted 6 times from the supernatant using ether, before lyophilization and storage at $-20^{\circ} \mathrm{C}$.

\section{High pressure liquid chromatography (HPLC) measurements}

Lyophilized brain extracts $(40 \mathrm{mg})$ were dissolved in $1 \mathrm{ml}$ deionized water, and $50 \mu \mathrm{l}$ aliquots were treated with $0.8 \mathrm{mg} \mathrm{N}$-acetyl-cysteine and $0.25 \mathrm{mg} o$-phthaldialdehyde in a $0.1 \mathrm{M}$ borate buffer, $\mathrm{pH} 10.4$, for derivatization of amino acids. HPLC measurements were performed using a Waters Alliance instrument (Waters Corporation, Guyancourt, France) with a Waters symmetry column $(4.6 \times 250 \mathrm{~mm})$. The column and sample compartments were kept at 30 and $8^{\circ} \mathrm{C}$ respectively. Flow rate was set at $1 \mathrm{ml} / \mathrm{min}$ and run time was $20 \mathrm{~min}$ for all analyses. $\mathrm{L}-$ and D- 
serine were eluted with an isocratic method using phase A $(990 \mathrm{ml}$ of $0.1 \mathrm{M}$ sodium acetate and $10 \mathrm{ml}$ tetrahydrofurane, $\mathrm{pH} 6.2$ ); the column was washed using phase $\mathrm{B}$ (500 $\mathrm{ml}$ of $0.1 \mathrm{M}$ sodium acetate, $470 \mathrm{ml}$ acetonitrile, $30 \mathrm{ml}$ tetrahydrofurane, $\mathrm{pH}$ 6.2). Amino acid derivatives were detected using a Waters fluorescence detector (excitation $344 \mathrm{~nm}$, emission $443 \mathrm{~nm}$ ), and data were acquired using the Empower Pro software package (Waters Corporation, Guyancourt, France). Calibration of D-serine detection was performed using a 7-point standard curve.

\section{In vivo experiments}

Rats were anesthetized with a ketamine-xylazine mixture $(42 \mathrm{mg} / \mathrm{ml}$ ketamine, $1,6 \mathrm{mg} / \mathrm{ml}$ xylazine, purchased from Centravet, Plancoët, France, and injected at $0.2 \mathrm{ml} / 100 \mathrm{~g}$ body weight) and placed in a stereotaxic apparatus (Stoelting Corporation, Wood Dale, $\mathrm{IL}$ ). Body temperature was kept at $37^{\circ} \mathrm{C}$ with a homeothermic blanket (LSI Letica, Barcelona, Spain). An active RgDAAO biosensor was implanted in the frontal cortex $(1 \mathrm{~mm}$ lateral from the midline, $3 \mathrm{~mm}$ anterior from the bregma, $1.5 \mathrm{~mm}$ ventral from the dura), side by side $(0.5 \mathrm{~mm})$ with a control biosensor covered with BSA. Both microbiosensors were covered with an additional Nafion layer. Before to start the recording, currents were allowed to stabilize for at least $30 \mathrm{~min}$. D-serine $1 \mathrm{~g} / \mathrm{kg}$ body weight was injected intraperitoneally after an additional $30 \mathrm{~min}$ period of control recording. In order to determine their selectivity and sensitivity, both biosensors were calibrated using 5-HT $20 \mu \mathrm{M}$ and D-serine $1 \mu \mathrm{M}$ dissolved in an artificial extracellular medium (see above) before and after the in vivo experiment.

\section{Statistics}


Data are expressed as mean \pm standard deviation (SD) except for in vivo or brain extracts measurements, where we used mean \pm standard error of the mean (SEM). Comparisons between two data groups were performed using the Student's $t$-test for equal or unequal variances, as determined by the F-test (significance level was $\mathrm{p}<0.05$ ). Statistics software was the analysis tool-pack

of

Excel

(Microsoft

Office

XP). 


\section{RESULTS AND DISCUSSION}

\section{Principle of D-serine detection by the biosensor}

D-serine detection was achieved by a two-step reaction using the enzyme DAAO: (1) DAAO converts D-amino acids into their corresponding $\alpha$-ketoacids (hydroxypyruvate for Dserine) and generates equimolar amounts of $\mathrm{H}_{2} \mathrm{O}_{2}$; (2) $\mathrm{H}_{2} \mathrm{O}_{2}$ is oxidized at the surface of a platinum wire connected to a patch-clamp amplifier (Fig 1). The resulting $\mathrm{H}_{2} \mathrm{O}_{2}$ oxidation current corresponds to the D-serine concentration in the biosensor's microenvironment.

To optimize $\mathrm{H}_{2} \mathrm{O}_{2}$ detection by the microbiosensor, we generated cyclic voltammograms in a solution of $\mathrm{H}_{2} \mathrm{O}_{2} 100 \mu \mathrm{M}$ in $\mathrm{PBS} 0.01 \mathrm{M} \mathrm{pH} 7.4$, using potential sweeps from $0 \mathrm{mV}$ to 900 $\mathrm{mV}$ vs. $\mathrm{Ag} / \mathrm{AgCl}$ reference electrode. As described by other authors ${ }^{47,}{ }^{48}$, holding potentials around $0 \mathrm{mV}$ gave rise to electrochemical reduction of $\mathrm{H}_{2} \mathrm{O}_{2}$, whereas oxidation was achieved above $+200 \mathrm{mV}$. Optimal $\mathrm{H}_{2} \mathrm{O}_{2}$ detection was performed at a holding potential of $+500 \mathrm{mV}$ vs. $\mathrm{Ag} / \mathrm{AgCl}$ reference electrode, at which background currents were kept minimal. This value falls in the $+500 \mathrm{mV}$ and $+700 \mathrm{mV}$ range $\mathrm{vs}$. $\mathrm{Ag} / \mathrm{AgCl}$ reference electrode typically used for platinum wire enzymatic biosensors $27,33,49,50$

\section{Choice of the DAAO}

The most commonly used and commercially available DAAO is the one isolated from pig kidney (pkDAAO). Several biosensors for D-amino acids detection in food samples have been successfully prepared using $\mathrm{pkDAAO}^{41-44}$. However, these biosensors achieved detection limits in the $10^{-5}-10^{-4} \mathrm{M}$ range, which is not sufficient for detecting D-serine extracellular concentration 
in the CNS, estimated at a few $10^{-6} \mathrm{M}^{20-22}$. This low sensitivity to D-amino acids might be due to the low specific activity of pkDAAO used for these biosensors. However, the DAAO from the yeast Rhodotorula gracilis shows better properties for biotechnological applications. It binds the flavin adenine dinucleotide (FAD) cofactor with high affinity and shows a higher specific activity and stability compared to its mammalian counterpart ${ }^{51}$.

We thus compared the sensitivity and selectivity of microbiosensors prepared with either pkDAAO or RgDAAO. Sensitivity for D-serine was $42 \%$ higher with RgDAAO microbiosensors than with pkDAAO ones: $9.2 \pm 3.4 \mathrm{pA} / \mu \mathrm{M}(\mathrm{n}=30)$ vs. $6.5 \pm 2.0 \mathrm{pA} / \mu \mathrm{M}(\mathrm{n}=4)$ respectively (Table 1). Moreover, RgDAAO microbiosensors were more selective for $\mathrm{D}$-serine than pkDAAO ones. For example, RgDAAO microbiosensors showed much smaller electrochemical responses to Daspartate $(5.5 \%$ of the $\mathrm{D}$-serine response vs. $38.6 \%$ for pkDAAO, $\mathrm{n}=4$, Table 1$)$ and were also slightly less sensitive to $\mathrm{D}$-alanine $(104 \%$ of $\mathrm{D}$-serine response vs. $165 \%$ for pkDAAO, $\mathrm{n}=4$, Table 1). Because D-aspartate and D-alanine can also be found in the mammalian CNS, together with D-serine ${ }^{52,53}$, the lower electrochemical responses produced by the RgDAAO biosensor to these D-amino acids would contribute to a greater selectivity in vivo. For these reasons, biosensors were prepared using RgDAAO in the rest of this study.

\section{In vitro detection of $\mathrm{D}$-serine}

We first calibrated the RgDAAO microbiosensors in D-serine standard solutions. The electrodes responded to changes in D-serine concentration by a step increase in the recorded oxidation current (Fig. 2A). The response time of the microbiosensors, defined as the duration of the rise between $10 \%$ and $90 \%$ of the response, was $2 \pm 1 \mathrm{~s}(\mathrm{n}=5$, Fig. $2 \mathrm{~B})$. 
D-serine oxidation current showed a linear relationship with concentration from $100 \mathrm{nM}$ to $500 \mu \mathrm{M}$, with a sensitivity of $9.2 \pm 3.4 \mathrm{pA} / \mu \mathrm{M}$ D-serine (n=25, Fig. $2 \mathrm{C}$ ). Importantly, only the electrodes showing a sensitivity higher than $7 \mathrm{pA} / \mu \mathrm{M}$ D-serine were used for further studies (see Experimental section). When the recorded signal was averaged at 1 data point/s, the noise was about $0.05 \mathrm{pA}$, yielding a theoretical detection limit of $16 \mathrm{nM}$ (signal/noise $=3$ ). This detection limit is significantly lower than the estimated D-serine concentration in the $\mathrm{CNS}^{20-22}$ and is therefore compatible with in vivo detection of this D-amino acid.

\section{Oxygen dependence}

D-amino acid oxidases require $\mathrm{O}_{2}$ as a co-substrate to complete the catalytic cycle. In order to evaluate the dependence of $\mathrm{D}$-serine detection on $\mathrm{O}_{2}$ concentration, we performed similar calibration experiments using PBS in equilibrium with the ambient atmosphere, or saturated with $\mathrm{O}_{2}$ or $\mathrm{N}_{2}$ (Fig. 2C-D). Provided that $\mathrm{O}_{2}$ is non-limiting, the relationship between the amplitude of the step in oxidation current detected by the biosensor and D-serine concentration can be approximated by a Michaelis-Menten equation:

$$
C=\frac{C \max *[D-\operatorname{serine}]}{K m_{a p p}+[D-\text { serine }]}
$$

where $\mathrm{C}$ is the oxidation current, and $\mathrm{C}_{\max }$ and $\mathrm{K}_{\mathrm{m} \text {,app }}$ are analogous to the classical $\mathrm{V}_{\max }$ and $\mathrm{K}_{\mathrm{m}}$ kinetic parameters used for the equation of the free enzyme. In a $\mathrm{O}_{2}$-saturated medium, the response of the microbiosensor followed a Michaelis-Menten kinetics at least up to $2.5 \mathrm{mM}$ D-serine with a $\mathrm{K}_{\mathrm{m} \text {,app }}$ of $3.62 \pm 0.38 \mathrm{mM}$, and a $\mathrm{C}_{\mathrm{max}}$ of $54.2 \pm 12.5 \mathrm{nA}\left(\mathrm{n}=4\right.$, Fig. 2D). $\mathrm{K}_{\mathrm{m} \text {,app }}$ was significantly lower than the $K_{m}$ of the free enzyme in solution $\left(13.75 \mathrm{mM}^{51}\right)$. Such a difference between free and immobilized RgDAAO was reported previously ${ }^{54}$, and was attributed 
to the conformation of the immobilized enzyme and to a higher concentration of D-serine in the hydrophobic enzymatic layer compared to the solution (partitioning effect). When calibrated in air-equilibrated buffer, the microbiosensor yielded very similar responses to those obtained in $\mathrm{O}_{2}$ saturated medium (Fig. 2C-D). However, the calibration curve obtained in $\mathrm{N}_{2}$-saturated buffer deviated significantly from the ones obtained in the presence of $\mathrm{O}_{2}$ for $\mathrm{D}$-serine concentrations greater than $30 \mu \mathrm{M}$ (Fig. 2C-D). The oxidation current detected by the microbiosensor reached a plateau at about $8 \mathrm{nA}$, reflecting the decreased DAAO activity at low $\mathrm{O}_{2}$ concentrations. The calibrations in the 0-30 $\mu \mathrm{M}$ D-serine range show a weak dependence on $\mathrm{pO}_{2}$, like most biosensors based on the detection of enzymatically produced $\mathrm{H}_{2} \mathrm{O}_{2}{ }^{27,33,55}$. This weak dependence on $\mathrm{pO}_{2}$ is probably due to $\mathrm{O}_{2}$-regeneration during $\mathrm{H}_{2} \mathrm{O}_{2}$ oxidation on the $\mathrm{Pt}$ surface, that produces a concentration of $\mathrm{O}_{2}$ at which the rate of reoxidation of reduced DAAO is not limiting ${ }^{55}$. Because physiological D-serine concentrations in the CNS are expected around 5-10 $\mu \mathrm{M}^{20-22}, \mathrm{D}$ serine detection at our microbiosensor should not depend on local $\mathrm{pO}_{2}$, except, possibly, during pathological states like cerebral ischemia.

\section{pH and temperature dependence}

$\mathrm{D}$-serine detection by the biosensor showed the same $\mathrm{pH}$ dependence as RgDAAO in solution $^{51,56}$. The response at $10 \mu \mathrm{M}$ D-serine increased from $\mathrm{pH} 5.4$ to 8.0 , reached a maximum at $\mathrm{pH} 8.0-8.5$, and decreased at higher values $(\mathrm{n}=4$, Fig. $3 \mathrm{~A})$. The response at physiological $\mathrm{pH}$ (7.4) was $80.7 \%$ of the maximum response observed at $\mathrm{pH} 8.5$.

The temperature dependence of $\mathrm{D}$-serine detection was also similar to that of the free enzyme in solution ${ }^{51}$. The microbiosensor response to D-serine increased with temperature, from 
$15^{\circ} \mathrm{C}$ to $40^{\circ} \mathrm{C}$ ( $\mathrm{n}=4$, Fig $3 \mathrm{~B}$ ). Its sensitivity at $37^{\circ} \mathrm{C}$ (in vivo temperature) is $75 \%$ higher than that at $25^{\circ} \mathrm{C}$ (room temperature).

\section{Operational and storage stability}

The operational stability of the microbiosensors was estimated by placing the electrode in PBS and then adding $5 \mu \mathrm{M}$ D-serine to produce an electrochemical signal. One hour later, the recording medium was replaced and fresh D-serine was newly added. The microelectrode response was thus evaluated every hour for 6 hours, during which it was almost constantly exposed to $5 \mu \mathrm{M}$ D-serine. Under these conditions, response to $\mathrm{D}$-serine remained stable $(\mathrm{n}=4$, data not shown), indicating that (1) the enzyme was strongly fixed to the platinum wire and (2) the microbiosensor could be exposed to physiological D-serine concentrations for several hours without any alteration of its sensitivity.

Storage stability was evaluated for microbiosensors kept at $-20^{\circ} \mathrm{C}$ immediately after manufacturing. Microbiosensors were tested for their response to $5 \mu \mathrm{M} \mathrm{D}$-serine $8,21,28,35,84$ and 160 days after manufacturing. They were dried and frozen between each test. Response to Dserine remained unchanged ( $n=3$, data not shown), showing only $2 \%$ loss in sensitivity after more than 160 days of storage.

\section{Selectivity}

The preceding data demonstrate that our microbiosensor can reliably detect D-serine concentrations as low as a few tens of $\mathrm{nM}$ for several hours in standard solutions. However, in order to detect D-serine in complex biological media, it is necessary to achieve selective measurements avoiding the detection of other endogenous molecules present in vivo. Endogenous molecules can interfere in two ways: (1) direct oxidation on the surface of the platinum wire and 
(2) oxidation by the enzyme accompanied by $\mathrm{H}_{2} \mathrm{O}_{2}$ production. Both kinds of interference were investigated:

\section{1- Endogenous oxidizable molecules}

The major endogenous molecules susceptible to oxidation at a platinum surface at +500 $\mathrm{mV}$ vs. $\mathrm{Ag} / \mathrm{AgCl}$ reference electrode are serotonin (5-HT) and its metabolite 5hydroxyindolacetic acid (5-HIAA), dopamine and its metabolite dihydroxyphenylacetic acid (DOPAC), L-cysteine, ascorbic acid and uric acid. Biosensors using enzymes directly coated on a bare platinum wire or carbon fiber typically produce strong interfering oxidation currents in response to physiological concentrations of these endogenous molecules. For example, microbiosensors consisting in RgDAAO directly deposited on a bare Pt wire showed such interfering responses (Fig. 4A). An efficient strategy to overcome these non-specific signals is to deposit a layer of electropolymerized PPD onto the Pt wire $30,39,57,58$. This process is highly reproducible and generates a thin $(10 \mathrm{~nm})$, uniform membrane. The PPD layer forms a steric barrier that allows $\mathrm{H}_{2} \mathrm{O}_{2}$ diffusion but blocks larger molecules ${ }^{59}$. It has several advantages, including an easily controllable thickness, a good reproducibility and a good uniformity of the film ${ }^{57}$. Moreover, electropolymerized films of $\mathrm{m}$-phenylenediamine show superior selectivity compared to those prepared with its $\mathrm{p}$ - or o- isomers ${ }^{30}$. RgDAAO microbiosensors manufactured from a poly-m-phenylenediamine covered $\mathrm{Pt}$ wire showed a dramatic reduction $(97-99 \%)$ in the interfering responses produced by endogenous oxidizable molecules $(n=4$, Fig. 4B). By contrast, D-serine detection was only reduced by $12 \%$.

We also tested the operational stability of the PPD layer. As shown in Fig. 4C, the small response to $20 \mu \mathrm{M} 5$-HT remained stable for 6 hours (in PBS containing $5 \mu \mathrm{M}$ D-serine at room temperature), indicating that the PPD layer retained its ability to reject 5-HT over several hours. 
However the PPD layer had a tendency to lose its selectivity over several days, even when stored at $-20^{\circ} \mathrm{C}$. We found that it could be reactivated by dipping the microbiosensor for $1-2 \mathrm{~s}$ in a 100 $\mathrm{mM}$ m-phenylenediamine solution, at $700 \mathrm{mV} v s . \mathrm{Ag} / \mathrm{AgCl}$ reference electrode. This procedure barely affected the sensitivity of the microbiosensor and restored the original selectivity. Overall, these results show that interfering responses caused by endogenous oxidizable molecules are reduced by more than $97 \%$ by an electropolymerized film of m-phenylenediamine. Importantly, this selectivity layer decreases the responses to physiological concentrations of these interfering molecules to a negligible level compared to D-serine oxidation currents.

\section{2-Other D-amino acids}

Free $\operatorname{RgDAAO}$ in solution preferentially oxidizes neutral $\mathrm{D}$-amino acids (such as $\mathrm{D}$ alanine, D-proline, D-cysteine, D-valine and D-serine), shows low activity towards basic ones and is practically inactive on acidic D-amino acids ${ }^{51}$. As expected, our RgDAAO microbiosensors generated large electrochemical responses not only to D-serine, but also to other D-amino acids, with the exception of D-aspartate and D-glutamate $(6.5 \%$ and $1.7 \%$ respectively of the D-serine response at the same concentration, n=4, Fig. 5A). Glycine also generated very small responses $(3.5 \%$ of $\mathrm{D}$-serine response, $\mathrm{n}=4$, Fig. $5 \mathrm{~A}$ ) whereas $\mathrm{L}$-amino acids were not detected $(<1.5 \%$ of $\mathrm{D}$-serine response for L-serine and L-cysteine, $\mathrm{n}=4$, Fig. $5 \mathrm{~A})$. Therefore, and consistent with earlier reports ${ }^{54}, \operatorname{RgDAAO}$ showed a broader substrate specificity when fixed on the microbiosensor than the free form, in particular, an increased activity towards basic amino acids.

In a recent study, Hamase et al. ${ }^{53}$ showed that D-serine was the predominant D-amino acid in the CNS, followed by D-aspartate (about $10 \%$ of D-serine contents), which is not detected by the microbiosensor, and by D-alanine ( $<3 \%$ of $\mathrm{D}$-serine contents), which is a good substrate 
for RgDAAO (Fig. 5B). Therefore, the new RgDAAO microbiosensor would be selective for Dserine when used in the CNS, since interference from endogenous D-amino acids is negligible compared to D-serine signals.

\section{Validation of the microbiosensor on brain extracts}

To confirm the selectivity of the microbiosensor, we measured D-serine concentrations in brain extracts, comparing amperometric recordings and HPLC analysis. Both methods yielded comparable D-serine concentrations $(130 \pm 7 \mu \mathrm{M}$ for HPLC vs. $139 \pm 8 \mu \mathrm{M}$ for the microbiosensor, $n=6$, NS, Fig. 6C): amperometric detection using the microbiosensor differed from HPLC analysis by only $6 \%$. To better quantify the amount of non-specific signals detected by the microbiosensor in the brain extracts, we eliminated D-serine (and other DAAO substrates) by incubating the sample for 2 hours with $20 \mathrm{U}$ of RgDAAO and $200 \mathrm{U}$ of catalase. This enzymatic treatment completely eliminated the D-serine peak in the HPLC chromatograms (Fig. $6 \mathrm{~A})$ and reduced the amperometric signal by $95.0 \pm 1.3 \%(n=6, p<0.01$, Fig. $6 \mathrm{~B})$. This result confirms that the sum of interfering signals detected by the microbiosensor in brain extracts is about $5-6 \%$ of the D-serine signal, and that our RgDAAO microbiosensor specifically detects Dserine when used in the CNS.

\section{In vivo detection of $\mathrm{D}$-serine}

We then implanted our microbiosensors in the frontal cortex of anesthetized rats. The RgDAAO microbiosensor was implanted close to a control biosensor (devoid of DAAO) used to control for non-specific variations in oxidation current. Both microbiosensors were coated with an additional layer of Nafion to optimize biocompatibility (see Experimental Section). 
Implantation in the CNS produced a small decrease in sensitivity $(-13.2 \%, 10.05 \pm 1.03 \mathrm{pA} / \mu \mathrm{M}$ D-serine before, $8.72 \pm 0.97 \mathrm{pA} / \mu \mathrm{M}$ after in vivo implantation, $\mathrm{n}=8$ ). This decrease in sensitivity is common to virtually all microbiosensors and generally occurs during the first 15 min following insertion into the brain ${ }^{60}$.

About $1 \mathrm{hr}$ after implantation into the CNS, the background currents stabilized, showing a difference of $47.2 \pm 7.5 \mathrm{pA}(\mathrm{n}=6)$ between the control and RgDAAO microbiosensor. This difference was not detected in calibrations made in PBS or in an artificial extracellular medium of ionic composition close to that of the rat cerebrospinal fluid $(2.3 \pm 1 \mathrm{pA}, \mathrm{n}=7)$. Because the control electrode and the $\operatorname{RgDAAO}$ microbiosensor were equally sensitive to endogenous oxidizable molecules like $\mathrm{H}_{2} \mathrm{O}_{2}$, ascorbate, etc., and because D-serine is the predominant Damino acid in the brain, the difference in background current mostly reflected the ambient basal D-serine concentration in the frontal cortex. To estimate the D-serine concentration represented by this difference in background currents, we calibrated our microbiosensors in artificial extracellular solution. In this medium, the sensitivity of the microbiosensor was unchanged compared to PBS. Moreover, addition of a physiological concentration $(400 \mu \mathrm{M})$ of ascorbate in the recording medium did not change the sensitivity of the microbiosensor ( $n=3$, data not shown). Using these calibration experiments, we estimated the basal extracellular D-serine concentration in the rat frontal cortex under ketamine-xylazine anesthesia at $3.1 \pm 0.4 \mu \mathrm{M}$. This value is of the same order of magnitude as other estimations based on microdialysis experiments $(6-8 \mu \mathrm{M})^{20-22}$.

We then injected $1 \mathrm{~g} / \mathrm{kg} \mathrm{D}$-serine intraperitoneally. It induced a steady increase in oxidation current at the $\operatorname{RgDAAO}$ microbiosensor, but not at the control sensor, indicating that the electrochemical signal detected by the RgDAAO microbiosensor was specific for D-serine. This increase in electrochemical signal was most probably due to the diffusion of D-serine across 
the blood-brain barrier. Three hours after the injection, the increase in oxidation current at the RgDAAO microbiosensor was $65.3 \pm 14.2 \mathrm{pA}$ whereas the background current at the control microbiosensor decreased by $5.8 \pm 1.8 \mathrm{pA}$ ( $\mathrm{n}=6$, Fig. 7). Using the same calibration experiments in artificial cerebrospinal fluid, we estimated that the D-serine extracellular concentration increased by $4.8 \mu \mathrm{M}$, to reach a final $7.9 \pm 1.2 \mu \mathrm{M}$ at the end of the 3 hour recording following the peripheral injection. This modest increase in D-serine concentration is in agreement with previous measurements made post-mortem on whole tissue ${ }^{61}$. However, these data contrast with an earlier report using microdialysis, that showed a much faster 6-fold increase in D-serine levels following the intraperitoneal injection of a smaller dose of D-serine $(50 \mathrm{mg} / \mathrm{kg})^{62}$. Indeed, implantation of microdialysis probes in the brain usually produces significant tissue damage, especially to neighboring blood vessels ${ }^{24,25}$. This problem might have led to an overestimation of D-serine diffusion into the brain. In this respect, biosensors of micrometric size seem preferable for studies requiring integrity of the blood-brain barrier $^{25}$. In particular, the slow and modest increase in D-serine levels detected by our microbiosensors after the peripheral $\mathrm{D}$-serine injection, suggests that damage to the blood-brain barrier produced upon implantation of the electrodes in the frontal cortex was indeed minimal.

\section{Conclusion}

Overall, these data demonstrate that D-serine levels in the CNS can be monitored using platinum-wire microbiosensors coated with the enzyme RgDAAO. This is the first report, to our knowledge, showing successful detection of $\mathrm{D}$-serine concentrations in vivo at the micromolar level using an amperometric biosensor. Compared to previous DAAO biosensors used for Damino acid detection in food, D-serine detection in vivo requires an increased selectivity, a higher 
sensitivity, and miniaturization to allow implantation in the CNS of small laboratory animals. These technical challenges have been overcome through (1) the use of RgDAAO, a more active and more selective enzyme than the previously used pkDAAO, (2) the development of micrometric platinum wire electrodes for $\mathrm{H}_{2} \mathrm{O}_{2}$ monitoring, and (3) the use of a highly selective PPD layer to block the non-specific oxidation of endogenous oxidizable molecules.

This new device will now pave the way for a better understanding of the physiological and pathological situations that lead to changes in D-serine levels in the CNS as well as the cellular mechanisms of D-serine release and elimination. It will also provide a powerful analytical tool for screening new pharmacological agents designed to modify D-serine metabolism in the CNS, in order to improve current treatments for neurological and psychiatric disorders such as schizophrenia ${ }^{62}$. 


\section{ACKNOWLEDGEMENTS}

This work was supported by the Centre National de la Recherche Scientifique, grants from Fondation pour la Recherche Médicale (bourse de retour 2004), Marie Curie Program (MIRGCT-2005-017196 - SERELAS) and Agence Nationale pour la Recherche (ANR-06-EMPB-029, SERICAP) to SM, a NATO Collaborative Linkage Grant (CBP.NUKR.CLG 982788) and EGIDE ECO-NET program (\#126758G) to AS and RC, and by grants from FAR to MP and LP, and from Fondazione CARIPLO to LP. PP is the recipient of a fellowship from Université Paris Sud. We are grateful to Sophie Luco and Josianne Thierry for their valuable assistance in HPLC experiments. We are indebted to Olexandr Soldatkin for participating in manufacturing and calibrating microbiosensors. 


\section{References}

(1) Hashimoto, A.; Nishikawa, T.; Hayashi, T.; Fujii, N.; Harada, K.; Oka, T.; Takahashi, K. FEBS Lett 1992, 296, 33-36.

(2) Oliet, S. H.; Mothet, J. P. Glia 2006, 54, 726-737.

(3) Wolosker, H.; Sheth, K. N.; Takahashi, M.; Mothet, J. P.; Brady, R. O., Jr.; Ferris, C. D.; Snyder, S. H. Proc Natl Acad Sci U S A 1999, 96, 721-725.

(4) Kartvelishvily, E.; Shleper, M.; Balan, L.; Dumin, E.; Wolosker, H. J Biol Chem 2006, $281,14151-14162$.

(5) Williams, S. M.; Diaz, C. M.; Macnab, L. T.; Sullivan, R. K.; Pow, D. V. Glia 2006, 53, 401-411

(6) Schell, M. J.; Molliver, M. E.; Snyder, S. H. Proc Natl Acad Sci U S A 1995, 92, 39483952.

(7) Mothet, J. P.; Pollegioni, L.; Ouanounou, G.; Martineau, M.; Fossier, P.; Baux, G. Proc Natl Acad Sci U SA 2005, 102, 5606-5611.

(8) Mothet, J. P.; Parent, A. T.; Wolosker, H.; Brady, R. O., Jr.; Linden, D. J.; Ferris, C. D.; Rogawski, M. A.; Snyder, S. H. Proc Natl Acad Sci U S A 2000, 97, 4926-4931.

(9) Yang, Y.; Ge, W.; Chen, Y.; Zhang, Z.; Shen, W.; Wu, C.; Poo, M.; Duan, S. Proc Natl Acad Sci US A 2003, 100, 15194-15199.

(10) Panatier, A.; Theodosis, D. T.; Mothet, J. P.; Touquet, B.; Pollegioni, L.; Poulain, D. A.; Oliet, S. H. Cell 2006, 125, 775-784. 
(11) Chumakov, I.; Blumenfeld, M.; Guerassimenko, O.; Cavarec, L.; Palicio, M.; Abderrahim, H.; Bougueleret, L.; Barry, C.; Tanaka, H.; La Rosa, P.; Puech, A.; Tahri, N.; Cohen-Akenine, A.; Delabrosse, S.; Lissarrague, S.; Picard, F. P.; Maurice, K.; Essioux, L.; Millasseau, P.; Grel, P.; Debailleul, V.; Simon, A. M.; Caterina, D.; Dufaure, I.; Malekzadeh, K.; Belova, M.; Luan, J. J.; Bouillot, M.; Sambucy, J. L.; Primas, G.; Saumier, M.; Boubkiri, N.; Martin-Saumier, S.; Nasroune, M.; Peixoto, H.; Delaye, A.; Pinchot, V.; Bastucci, M.; Guillou, S.; Chevillon, M.; Sainz-Fuertes, R.; Meguenni, S.; Aurich-Costa, J.; Cherif, D.; Gimalac, A.; Van Duijn, C.; Gauvreau, D.; Ouellette, G.; Fortier, I.; Raelson, J.; Sherbatich, T.; Riazanskaia, N.; Rogaev, E.; Raeymaekers, P.; Aerssens, J.; Konings, F.; Luyten, W.; Macciardi, F.; Sham, P. C.; Straub, R. E.; Weinberger, D. R.; Cohen, N.; Cohen, D. Proc Natl Acad Sci U S A 2002, 99, 1367513680.

(12) Shinkai, T.; De Luca, V.; Hwang, R.; Muller, D. J.; Lanktree, M.; Zai, G.; Shaikh, S.; Wong, G.; Sicard, T.; Potapova, N.; Trakalo, J.; King, N.; Matsumoto, C.; Hori, H.; Wong, A. H.; Ohmori, O.; Macciardi, F.; Nakamura, J.; Kennedy, J. L. Neuromolecular Med 2007, 9, 169-177.

(13) Katsuki, H.; Nonaka, M.; Shirakawa, H.; Kume, T.; Akaike, A. J Pharmacol Exp Ther 2004, 311, 836-844.

(14) Wu, S. Z.; Bodles, A. M.; Porter, M. M.; Griffin, W. S.; Basile, A. S.; Barger, S. W. J Neuroinflammation 2004, $1,2$.

(15) Sasabe, J.; Chiba, T.; Yamada, M.; Okamoto, K.; Nishimoto, I.; Matsuoka, M.; Aiso, S. Embo J 2007, 26, 4149-4159. 
(16) Hashimoto, K.; Engberg, G.; Shimizu, E.; Nordin, C.; Lindstrom, L. H.; Iyo, M. Prog Neuropsychopharmacol Biol Psychiatry 2005, 29, 767-769.

(17) Bendikov, I.; Nadri, C.; Amar, S.; Panizzutti, R.; De Miranda, J.; Wolosker, H.; Agam, G. Schizophr Res 2007, 90, 41-51.

(18) Tsai, G.; Yang, P.; Chung, L. C.; Lange, N.; Coyle, J. T. Biol Psychiatry 1998, 44, 1081 1089.

(19) Lane, H. Y.; Chang, Y. C.; Liu, Y. C.; Chiu, C. C.; Tsai, G. E. Arch Gen Psychiatry 2005, 62, 1196-1204.

(20) Hashimoto, A.; Oka, T.; Nishikawa, T. Neuroscience 1995, 66, 635-643.

(21) Matsui, T.; Sekiguchi, M.; Hashimoto, A.; Tomita, U.; Nishikawa, T.; Wada, K. $J$ Neurochem 1995, 65, 454-458.

(22) Ciriacks, C. M.; Bowser, M. T. Anal Chem 2004, 76, 6582-6587.

(23) O'Brien, K. B.; Esguerra, M.; Klug, C. T.; Miller, R. F.; Bowser, M. T. Electrophoresis 2003, 24, 1227-1235.

(24) Morgan, M. E.; Singhal, D.; Anderson, B. D. J Pharmacol Exp Ther 1996, 277, 11671176.

(25) Khan, A. S.; Michael, A. C. Trends Anal Chem 2003, 22, 503-508.

(26) Borland, L. M.; Shi, G.; Yang, H.; Michael, A. C. J Neurosci Methods 2005, 146, 149158.

(27) Hu, Y.; Mitchell, K. M.; Albahadily, F. N.; Michaelis, E. K.; Wilson, G. S. Brain Res 1994, 659, 117-125.

(28) Pomerleau, F.; Day, B. K.; Huettl, P.; Burmeister, J. J.; Gerhardt, G. A. Ann N Y Acad Sci 2003, 1003, 454-457. 
(29) Oldenziel, W. H.; Dijkstra, G.; Cremers, T. I.; Westerink, B. H. Brain Res 2006, 1118, $34-42$.

(30) Schuvailo, O. N.; Soldatkin, O. O.; Lefebvre, A.; Cespuglio, R.; Soldatkin, A. P. Anal Chim Acta 2006, 573-574, 110-116.

(31) Kulagina, N. V.; Shankar, L.; Michael, A. C. Anal Chem 1999, 71, 5093-5100.

(32) Llaudet, E.; Botting, N. P.; Crayston, J. A.; Dale, N. Biosens Bioelectron 2003, 18, 43-52.

(33) Llaudet, E.; Hatz, S.; Droniou, M.; Dale, N. Anal Chem 2005, 77, 3267-3273.

(34) Garguilo, M. G.; Michael, A. C. JNeurosci Methods 1996, 70, 73-82.

(35) Parikh, V.; Pomerleau, F.; Huettl, P.; Gerhardt, G. A.; Sarter, M.; Bruno, J. P. Eur J Neurosci 2004, 20, 1545-1554.

(36) Mitchell, K. M. Anal Chem 2004, 76, 1098-1106.

(37) Bruno, J. P.; Gash, C.; Martin, B.; Zmarowski, A.; Pomerleau, F.; Burmeister, J.; Huettl, P.; Gerhardt, G. A. Eur J Neurosci 2006, 24, 2749-2757.

(38) Schuvailo, O. N.; Dzyadevych, S. V.; El'skaya, A. V.; Gautier-Sauvigne, S.; Csoregi, E.; Cespuglio, R.; Soldatkin, A. P. Biosens Bioelectron 2005, 21, 87-94.

(39) Netchiporouk, L. I.; Shram, N. F.; Jaffrezic-Renault, N.; Martelet, C.; Cespuglio, R. Anal Chem 1996, 68, 4358-4364.

(40) Shram, N. F.; Netchiporouk, L. I.; Martelet, C.; Jaffrezic-Renault, N.; Bonnet, C.; Cespuglio, R. Anal Chem 1998, 70, 2618-2622.

(41) Varadi, M.; Adanyi, N.; Szabo, E. E.; Trummer, N. Biosens Bioelectron 1999, 14, 335 340.

(42) Dominguez, R.; Serra, B.; Reviejo, A. J.; Pingarron, J. M. Anal Biochem 2001, 298, 275 282. 
(43) Wcislo, M.; Compagnone, D.; Trojanowicz, M. Bioelectrochemistry 2006.

(44) Wu, X.; Van Wie, B. J.; D.A., K. Biosens Bioelectron 2004, 20, 879-886.

(45) Pernot, P.; Mothet, J. P.; Schuvailo, O. N.; Soldatkin, A. P.; Pollegioni, L.; Pilone, M.; Cespuglio, R.; Marinesco, S.,The 14th International Conference on Solid-State Sensors, Actuators and Microsystems, Lyon 2007.

(46) Molla, G.; Vegezzi, C.; Pilone, M. S.; Pollegioni, L. Protein Expr Purif 1998, 14, 289294.

(47) Hall, S. B.; Khudaish, E. A.; Hart, A. L. Electrochimica Acta 1998, 43, 2015-2024.

(48) Cai, L. T.; Chen, H. Y. Sensors and Actuators B 1999, 55, 14-18.

(49) Burmeister, J. J.; Pomerleau, F.; Palmer, M.; Day, B. K.; Huettl, P.; Gerhardt, G. A. $J$ Neurosci Methods 2002, 119, 163-171.

(50) Dale, N.; Hatz, S.; Tian, F.; Llaudet, E. Trends Biotechnol 2005, 23, 420-428.

(51) Pollegioni, L.; Falbo, A.; Pilone, M. S. Biochim Biophys Acta 1992, 1120, 11-16.

(52) Hashimoto, A.; Nishikawa, T.; Oka, T.; Takahashi, K.; Hayashi, T. J Chromatogr 1992, $582,41-48$

(53) Hamase, K.; Konno, R.; Morikawa, A.; Zaitsu, K. Biol Pharm Bull 2005, 28, 1578-1584.

(54) Pilone, M. S.; Pollegioni, L.; Buto, S. Biotechnol. and Appl. Biochem. 1992, 16, 252-262.

(55) Oldenziel, W. H.; Dijkstra, G.; Cremers, T. I.; Westerink, B. H. Anal Chem 2006, 78, 3366-3378.

(56) Pollegioni, L.; Caldinelli, L.; Molla, G.; Sacchi, S.; Pilone, M. S. Biotechnol Prog 2004, $20,467-473$.

(57) Malitesta, C.; Palmisano, F.; Torsi, L.; Zambonin, P. G. Anal Chem 1990, 62, 2735-2740.

(58) Moussy, F.; Jakeway, S.; Harrison, D. J.; Rajotte, R. V. Anal Chem 1994, 66, 3882-3888. 
(59) Yuqing, M.; Jianrong, C.; Xiaohua, W. Trends Biotechnol 2004, 22, 227-231.

(60) Marinesco, S.; Carew, T. J. J Neurosci 2002, 22, 2299-2312.

(61) Hashimoto, A.; Chiba, S. Eur J Pharmacol 2004, 495, 153-158.

(62) Fukushima, T.; Kawai, J.; Imai, K.; Toyo'oka, T. Biomed Chromatogr 2004, 18, 813-819. 


\section{FIGURE CAPTIONS}

Figure 1: Design of the biosensor. A. Photomicrograph of the tip of a RgDAAO microbiosensor. The enzymatic layer appears as a translucid, yellow membrane. B. Schematic representation of the $\mathrm{D}$-amino acid oxidase ( $\mathrm{RgDAAO})$ microbiosensor. A platinum wire is covered with a layer of poly-m-phenylenediamine (PPD) and an enzymatic membrane of RgDAAO. C. Enzymatic reaction allowing D-serine detection at the microbiosensor: D-serine is oxidized into hydroxypyruvate by $\mathrm{RgDAAO}$ with equimolar production of hydrogen peroxide $\left(\mathrm{H}_{2} \mathrm{O}_{2}\right)$ that diffuses through the PPD layer and is oxidized by the platinum wire $\mathrm{H}_{2} \mathrm{O}_{2}$ oxidation gives rise to two electrons detected by the patch-clamp amplifier.

Figure 2: D-serine detection. A. Response of the biosensor to changes in D-serine concentration. The electrode was rapidly transferred from phosphate buffered saline (PBS) to a $500 \mathrm{nM}$ or $1 \mu \mathrm{M}$ D-serine solution and back to PBS. The change in D-serine concentration was detected as a step in the oxidation current recorded by the electrode B. Response time. The electrode was switched from 0 to $10 \mu \mathrm{M} \mathrm{D}$-serine. The response time was defined as the time between $10 \%$ and $90 \%$ of the current step. In order to obtain a higher time resolution, the signal was averaged over $10 \mathrm{~ms}$ (instead of $1 \mathrm{~s}$ ) C. Calibration curves of a microbiosensor at three oxygen concentrations ( $\mathrm{N}_{2}$-saturation, air equilibrated and $\mathrm{O}_{2}$-saturation) in the 0-50 $\mu \mathrm{M} \mathrm{D}$-serine concentration range. Except for the $\mathrm{N}_{2}$-saturated medium, the oxidation current shows a linear dependence on the D-serine concentration. D. Calibration curves of the microbiosensor in the 0- 
2.5 $\mathrm{mM} \mathrm{D}$-serine concentration range. The calibration was made in $\mathrm{N}_{2}$-saturated, in air equilibrated and in $\mathrm{O}_{2}$-saturated PBS. The relationship between the oxidation current and Dserine concentration fits with a classical Michaelis-Menten equation in which $\mathrm{O}_{2}$ is not-limiting in catalysis.

Figure 3: pH and temperature dependence. A. pH-dependence of $\mathrm{D}$-serine detection. $\mathrm{pH}$ was adjusted in $0.01 \mathrm{M}$ PBS from 5.4 to 8.0 and $0.01 \mathrm{M}$ borate from 8.3 to 11.5. Data are expressed as a percentage of the response at $\mathrm{pH} 8.0(n=4)$. B. Temperature-dependence of the microbiosensor response $(n=4)$. All measurements were performed in $10 \mu \mathrm{M}$ D-serine, PBS $0.01 \mathrm{M}, \mathrm{pH} 7.4$.

Figure 4: Selectivity of the biosensor. Responses of the biosensor to physiological concentrations of different interfering molecules present in the CNS, without (A) and with (B) the PPD layer $(n=4)$. The PPD layer dramatically decreased the sensitivity of the biosensor to interfering substances. C. Stability of the PPD layer. Electrochemical responses to 5-HT remained low for at least 6 hours of in vitro experiment at room temperature ( $\mathrm{n}=4$, measuring conditions: PBS $0.01 \mathrm{M}, \mathrm{pH} 7.4)$.

Figure 5: Detection of other amino acids. A. Detection of the D-isomers of the 20 standard amino acids, as well as glycine, L-serine and L-cysteine $(10 \mu \mathrm{M})$. Data are expressed as a percentage of the response obtained with $10 \mu \mathrm{M}$ D-serine $(n=4)$. As expected from the biochemical properties of RgDAAO, the biosensor detected all D-amino acids that we tested, except D-aspartate and D-glutamate. Glycine and L-amino acids produced negligible responses. 
B. Amounts of the most abundant D-amino acids in the mouse brain as reported by Hamase et $a l^{53}$. The predominant $\mathrm{D}$-amino acid is $\mathrm{D}$-serine (red), followed by $\mathrm{D}$-aspartate (blue) and $\mathrm{D}$ alanine (green).

Figure 6: D-serine detection in brain extracts. A. Example chromatogram showing separation between $\mathrm{D}$-serine (elution time $=12 \mathrm{~min}$ ) and L-serine $(=13 \mathrm{~min})$. The $\mathrm{D}$-serine peak completely disappeared after incubation with $\mathrm{RgDAAO}$ and catalase. B. Example of electrochemical responses recorded by the microbiosensor upon addition of a brain extract (40x dilution) and $3 \mu \mathrm{M}$ D-serine. The response almost disappeared when the brain extract was preincubated with RgDAAO and catalase. C. Summary of the results of D-serine concentrations in brain extracts estimated by HPLC and the RgDAAO biosensor. Both techniques yielded comparable results, thus indicating an excellent selectivity for $\mathrm{D}$-serine in brain extracts. * significant difference with $\mathrm{D}$-serine levels following DAAO incubation $(\mathrm{p}<0.05)$. Data are expressed as mean $\pm \operatorname{SEM}(\mathrm{n}=6)$.

Figure 7: D-serine detection in vivo. Effect of an intraperitoneal injection of D-serine (1 $\mathrm{g} / \mathrm{kg}$ body weight) on the electrochemical signal detected in the frontal cortex by a RgDAAO microbiosensor and a control (BSA) microbiosensor implanted in its vicinity (about $0.5 \mathrm{~mm}$ ). Background currents were systematically higher at the RgDAAO microbiosensor compared to the control electrode, revealing a detectable basal extracellular D-serine concentration. Peripheral Dserine injection produced a specific increase in oxidation current at the RgDAAO microbiosensor, reflecting D-serine diffusion across the blood brain barrier. Data are expressed as mean (solid line) \pm SEM (shading) of 6 experiments. 
Table 1: Response of microbiosensors produced with pkDAAO or RgDAAO on different D-amino acids. Sensitivity to D-serine, D-aspartate and D-alanine were assessed for the two microbiosensors. RgDAAO microbiosensors show greater sensitivity and improved selectivity for D-serine compared to pkDAAO ones $(n=4)$. 
Figure 1

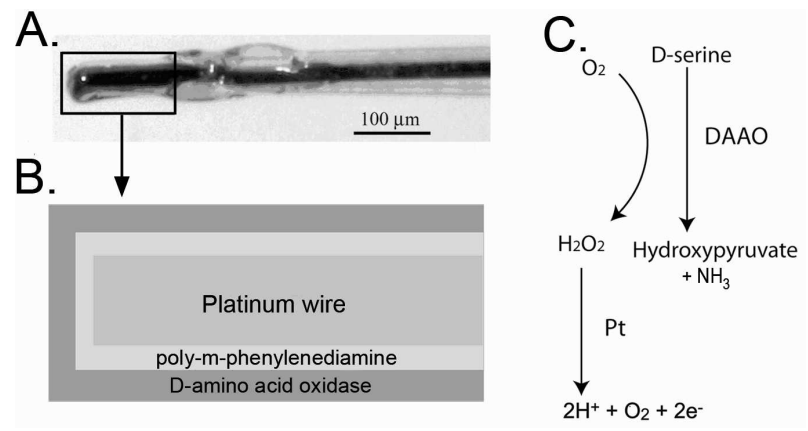


Figure 2

A.

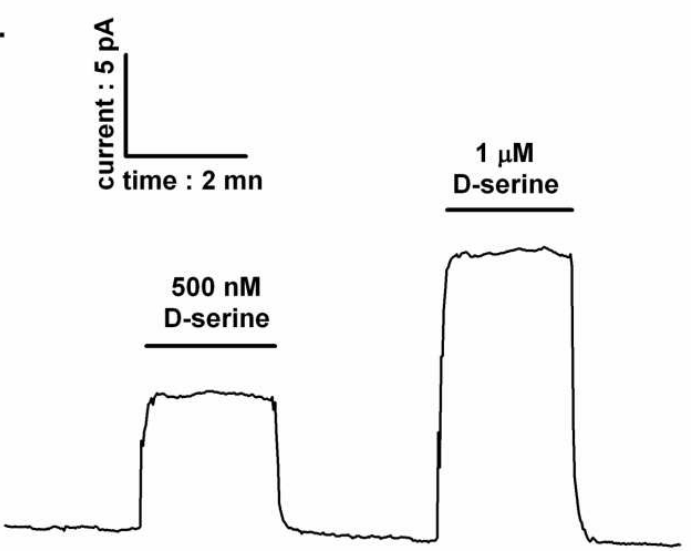

C.

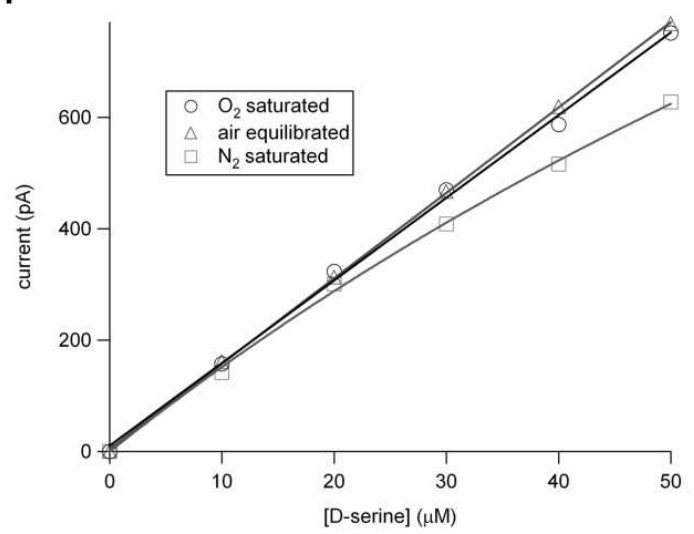

B.

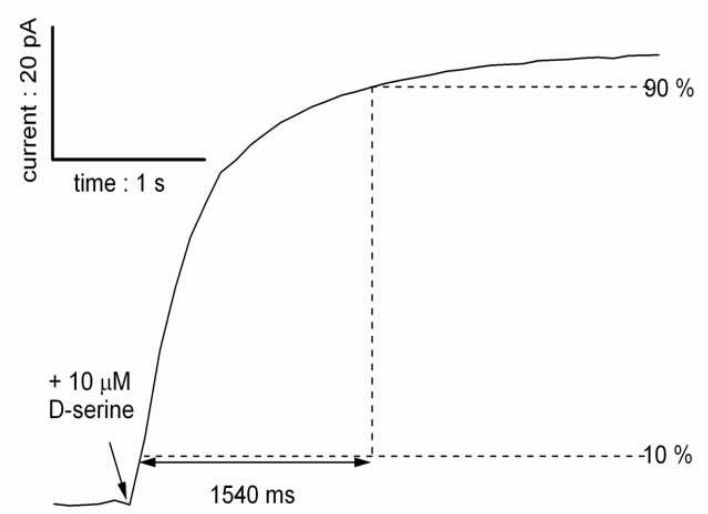

D.

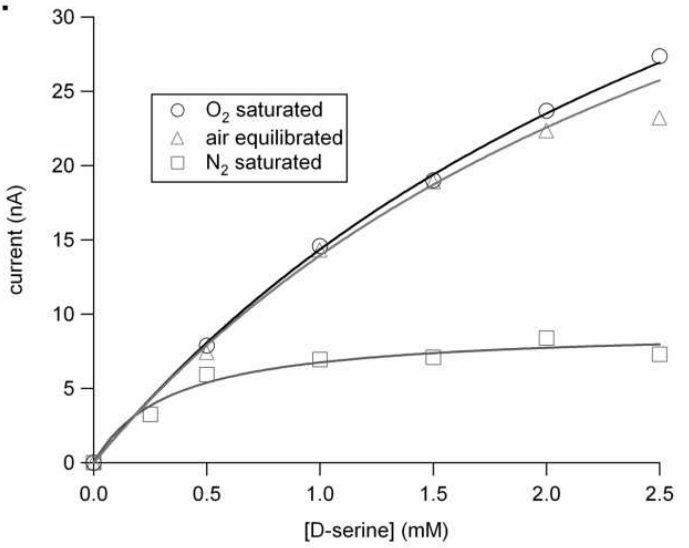


Figure 3
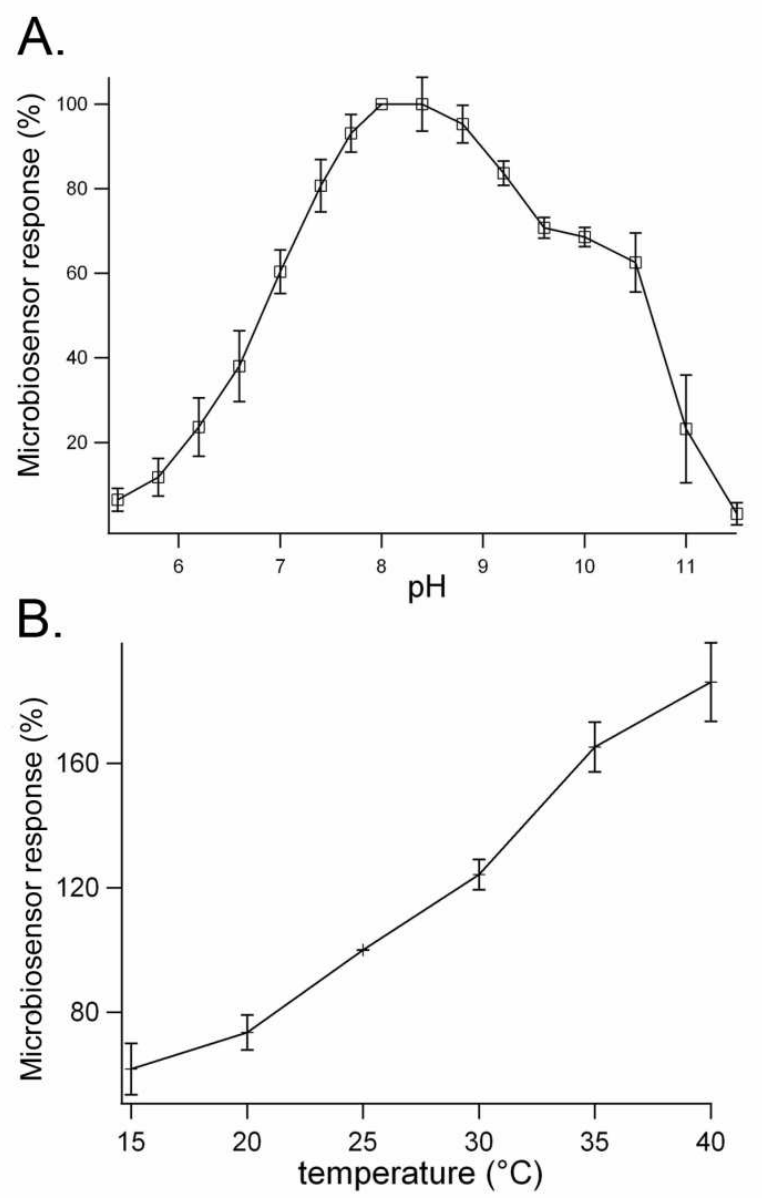
Figure 4

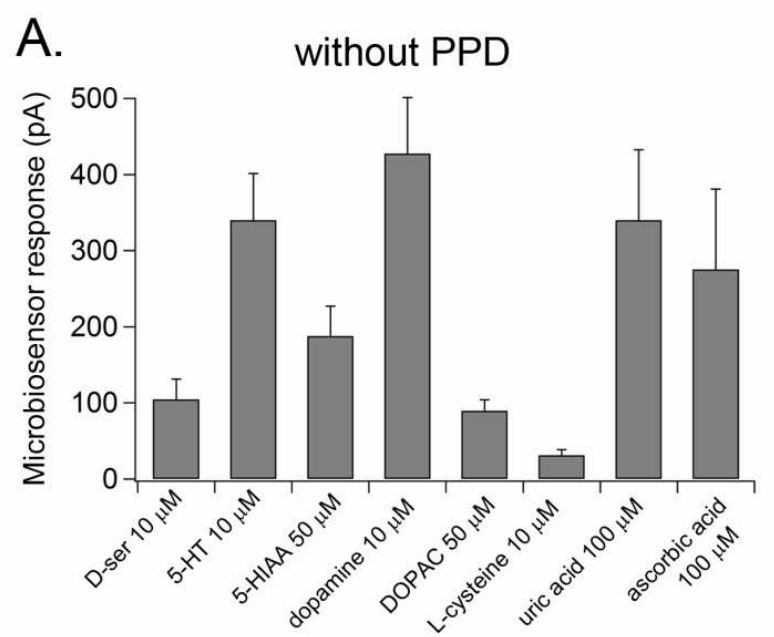

B.

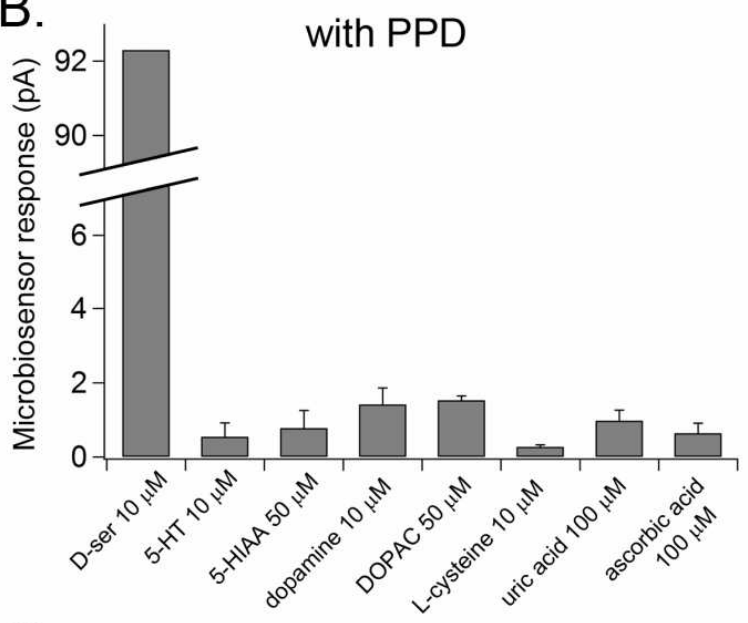

C.

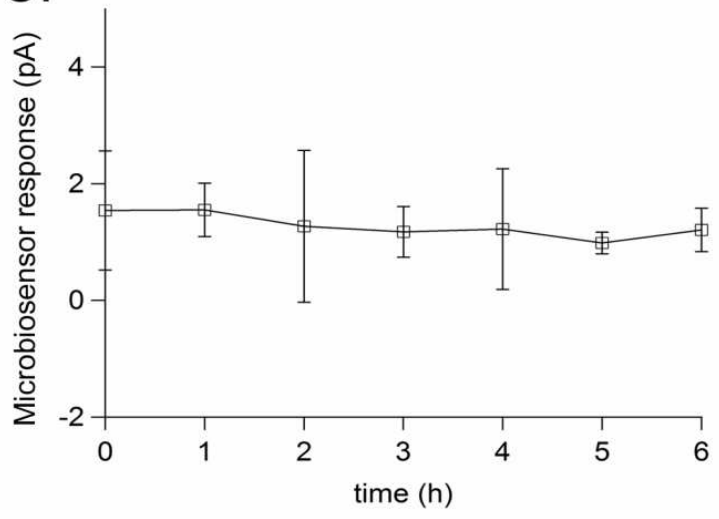


Figure 5

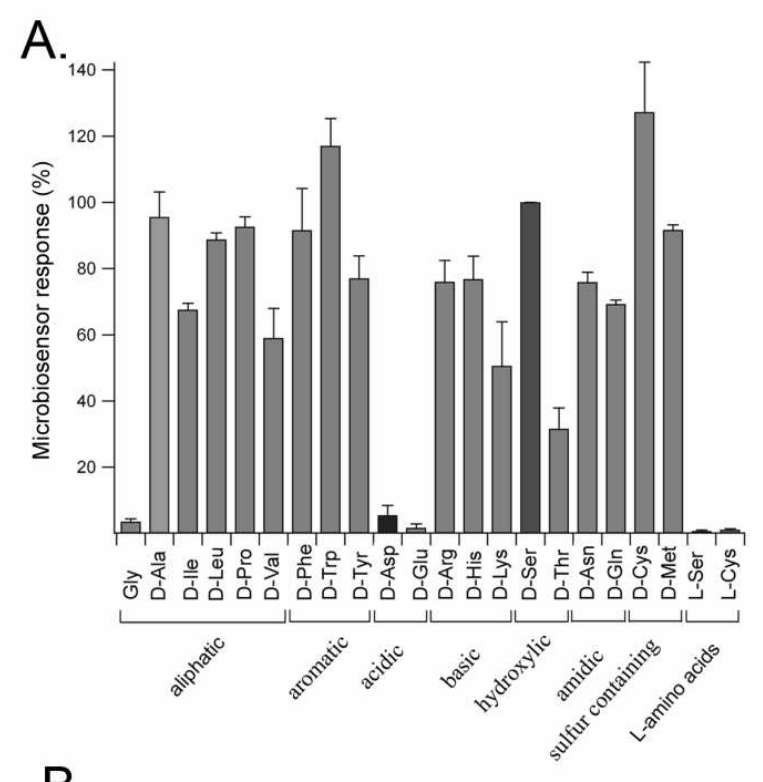

B.

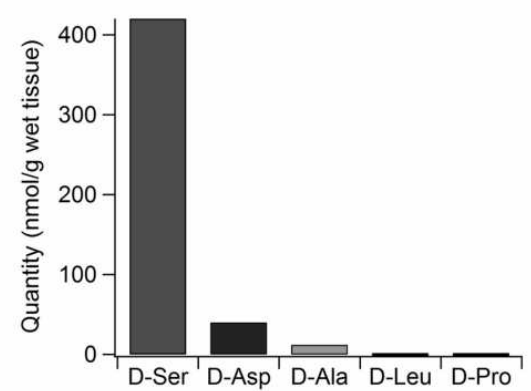


Figure 6

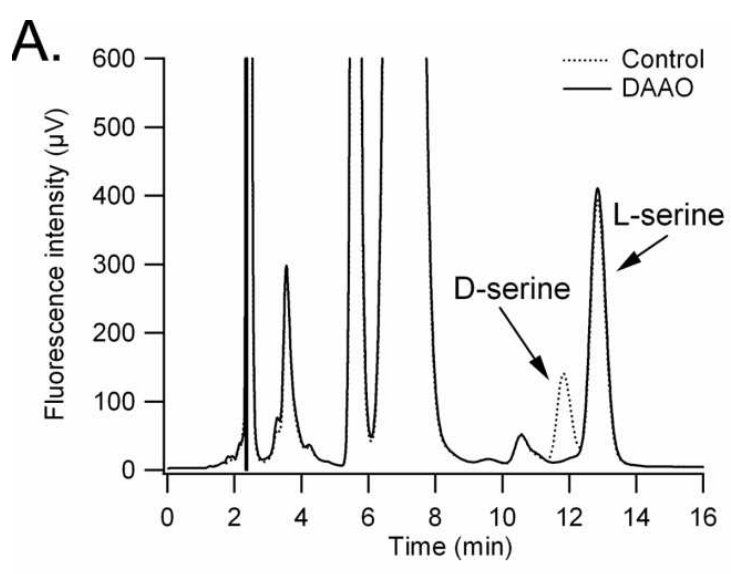

B.
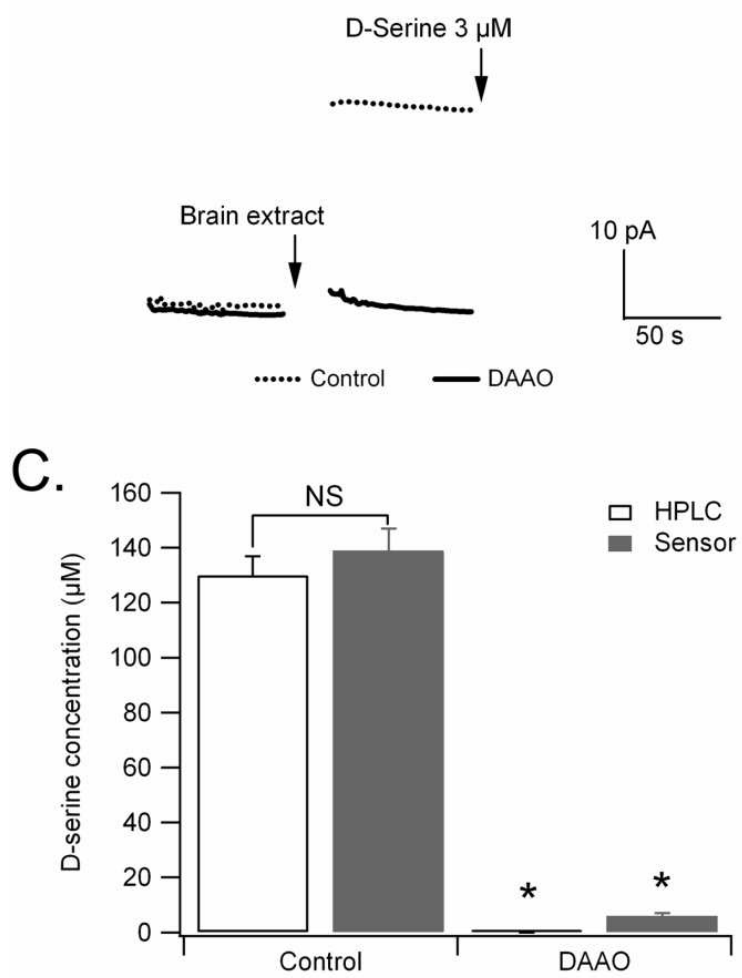
Figure 7

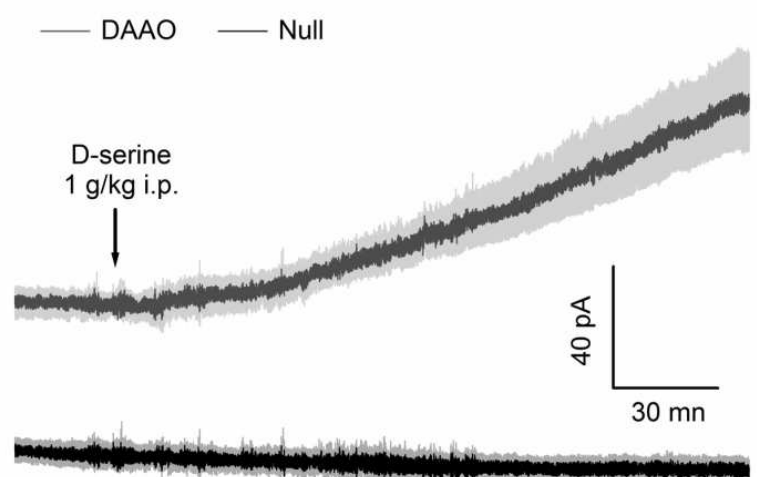


Table 1

\begin{tabular}{|c|c|c|c|c|}
\hline \multirow{2}{*}{ Substrate } & \multicolumn{2}{|c|}{ PKDAAO microbiosensor } & \multicolumn{2}{c|}{ RgDAAO microbiosensor } \\
\cline { 2 - 5 } & $\begin{array}{c}\text { Sensitivity } \\
(\mathrm{pA} / \mu \mathrm{M})\end{array}$ & $\begin{array}{c}\text { \% of D-serine } \\
\text { detection }\end{array}$ & $\begin{array}{c}\text { Sensitivity } \\
(\mathrm{pA} / \mu \mathrm{M})\end{array}$ & $\begin{array}{c}\text { \% of D-serine } \\
\text { detection }\end{array}$ \\
\hline D-Ser & $6.5 \pm 2.0$ & $100 \%$ & $9.2 \pm 3.4$ & $100 \%$ \\
\hline D-Asp & $2.5 \pm 0.8$ & $38.6 \%$ & $0.5 \pm 0.2$ & $5.5 \%$ \\
\hline D-Ala & $10.8 \pm 2.9$ & $165 \%$ & $9.6 \pm 1.4$ & $104 \%$ \\
\hline
\end{tabular}

